\title{
Organizational Trauma: A Phenomenological Study of Psychological Organizational Trauma and Its Effect on Employees and Organization
}

\author{
LARISSA WINTER \\ Galagan Advisory, Austria \\ l.winter@galaganadvisory.com
}

\begin{abstract}
Traumatology as scientific discipline has its roots in the early twentieth century. The rise of Psychoanalysis and the atrocities of two world wars, which victimized millions of soldiers and civilians worldwide, represent the foundation of Traumatology. Symptoms of Posttraumatic Stress Disorder (P TSD) were observed and studied systematically ever since. After introductory differentiations regarding the terminology of $\mathrm{PTSD}$ and resilience, this paper offers insight into organizational trauma. Both, the organizational context of trauma and the processes of transmitting traumata within organizations are described and analysed. This paper refers to a single case study, carried out in Austria during 2017/2018, investigating a collapsing mid-sized international bank and the traumatic impacts across its organizational structures. Narrative methods were used according to the study's research design, in order to explore how the traumatized employees 'storied' their experiences. Narrative thematic segments reveal how persons endure, cope with and eventually get over severe long-term traumatic experiences.
\end{abstract}

Key words: organizational trauma, posttraumatic stress disorder, resilience, coping strategies https://doi.org/10.26493/1854-4231.14.117-136

It was at the Salpêtrière, Europe's leading psychiatric hospital in Paris during the late 19th century, when French neurologist JeanMartin Charcot started to investigate stressful traumatic events as potential origins of so-called hysterical symptoms. Among Charcot's international students was also Sigmund Freud; the later founder of Psychoanalysis continued his studies of hysterical phenomena, thereby also laying the foundations for further research during World War I and the post war years. 


\section{Trauma Theory Revisited}

Multiple cases of soldiers with symptoms of Posttraumatic Stress Disorder (PTSD) were observed, ranging from hypersensitivity and panic attacks to amnesia, tinnitus and various symptoms of depression (Ringel and Brandell 2012). Merely some two decades later the catastrophic impacts of World War in started to bring about even deeper and chronic combat traumata of soldiers. On the part of civilians they resulted in countless severe and even life-long traumatization of many of the concentration-camp survivors. Eventually, the wars in Korea and Vietnam showed similar symptoms with regards to individuals confronted with overwhelming life events.

During the early 1960s' these first decades of scientific observations were synthesized to five core components, able to comprehensively describe traumata scientifically: a traumatic event creates a problem that cannot be solved in the immediate future. It surmounts an individual's psychological resources and problem solving capacities. It is perceived as potentially threatening regarding a person's life goals. The acute tension mounts to a peak and declines after that, and the event also awakens various unresolved problems from both, a person's near and distant past (Parad and Caplan 1960). Psychological Trauma and Posttraumatic Stress Disorder (PTSD) were included in the Diagnostic and Statistical Manual of Mental Disorders as of 1980 (American Psychiatric Association 1980).

In the course of the following decades the subsequent DSM-versions defined and differentiated five major categories of symptoms, thereby reflecting events that have the potential of being traumatic for the majority of people across most cultures and social classes (Ford et al. 2009): Intrusion symptoms, dissociative, avoidance, and arousal symptoms, as well as persistent inabilities to experience significant positive emotions. If at least nine different symptoms from any of the above mentioned categories prevail for more than three days, the criteria for acute stress disorder are met; in case of persisting severe problems, the criteria for PTSD are met (American Psychiatric Association 2013).

\section{PTSD and Resilience: Terminology and Differentiation}

Due to the detailed and clear terminology as of DSM-IV, it became possible to differentiate between recollecting, remembering and reexperiencing traumatic events (Wilson 1995), but also to distinguish between neurological and psychological hypersensitivity (Everly 1995). Single incident traumata were distinguished from complex 
or repetitive traumatic events, in order to be able to describe the adverse effects on a person's psychobiological growth and the various risk-levels of developing PTSD (Ford et al. 2009). Since neurobiological long-term effects of stress events can lead to reversible but also to permanent vulnerability to future events (Post 1992), elevated responses to reminders or associations of traumatic experiences can occur years or even decades after the actual event. They can trigger most vivid recollections of these events (Kolk 2007). Initial assumptions that PTSD occurred only rarely, were revised during the last decades, showing that factors such as irreparability, unpredictability, and uncontrollability were central to developing PTSD (Ford et al. 2009; McFarlane and Girolamo 2007).

The probabilities of traumatic events to eventually lead to PTSD depend on various factors, such as age, sex and the actual underlying causes, from severe injuries to war or witnessing death. Resilience is among the factors that prevent PTSD from developing to its maximum impact. It is a person's 'ability to bend and not break' (Bridges 1995, 56); a process during which a person regains stability and levels of functioning, despite being confronted with severe adversity (Bhamra et al. 2011; Caza and Milton 2012). The phenomenon of resilience contains both, elements of personality traits but also individual resources that can be activated in view of traumatizing events, in order to adapt and to maintain mental stability (Vogus et al. 2014; Bonanno 2004). Being exposed to very stressful and highly disruptive events, but displaying average levels of normal functioning instead of developing PTSD, can be the result of two trajectories: some individuals recover more quickly, some are able to endure better and adjust more easily.

Resilience ranges from the absence of psychopathological symptoms in persons who experience extreme life events, to disruptive and critical working environments providing continuous stressors that can have unfavourable long-term effects. Another characteristic of resilience is the capability of individuals during periods of bereavement to maintain 'continuity in identity from the preloss past to the postloss present' (Bonanno, Papa, and O'Neill 2002, 195). Trauma Theory has been predominantly focusing on the symptoms of PTSD; the gradual shift towards the phenomenon of maintaining baseline levels of daily routines and functioning, has only been studied intensely during the past two decades (Bonanno and Mancini 2012). The exposure of different individuals to the same or to similar traumatic events in terms of proximity, intensity, and length of time, may lead to rather different reactions (Bonanno et al. 2015). At the same 
time individuals may also display substantial differences regarding the capacity of endurance of the same stressors and comparable adversities. Developing resilience is not only important in an individual's personal and social life; it is also vital within today's organizations facing uncertain environments, disruptive processes and accelerating change (Bhamra and Burnard 2011).

\section{The Organizational Context of Trauma}

Individuals within organizations but also entire organizational structures with their vertical and horizontal differentiations can suffer from traumatic impacts on all of their levels. The various dimensions of disruptive effects caused by traumatic single events or traumata that develop over a long period of time can weigh upon both, the organizational structures and hierarchical systems. Their spillover effects can eventually take a heavy toll on the structural stability, flexibility and responsiveness of organizations. The dysfunctional patterns and perturbations caused by traumatic events and their potentially long-lasting organizational effects are challenges that organizations face, when coping with 'the unexpected' (Sutcliffe and Christianson 2012, 843).

The susceptibility to organizational trauma depends on various factors that lie within the organizations themselves, their functional structures, processes and systems. Organizational pathologies exist in almost every economic system. However, at the basis of any organizational functioning lie elements which enable organizations to develop effectiveness and efficiency in the first place. These underlying elements are circumscribable as organizational culture (Schein 2010), which encompasses all hierarchical levels, from the 'strategic apex' to the 'operating core' (Mintzberg 1983, 262).

Emerging stressors, declines of corporate controllability, and other developments that eventually lead to traumatic episodes or events, have negative impacts on organizational structures, well established corporate processes. However, traumatic events within organizations rarely occur in the form of natural disasters, without any signs or prior warnings. Such sudden and catastrophic events are rare exceptions, caused by e.g. technological failures in certain areas of complex, high-risk technologies (Reason 2016). In most cases of organizational disasters however, the path towards adversity and traumatic events can be described as an accumulation of small and mediumsized mistakes, overlooked minor problems, unsafe acts and shortcomings in the field of supervision (Sutcliffe and Christianson 2012; Kleber and Velden 2009).

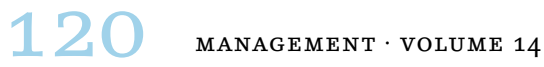




\section{Transmitting Trauma within Organizations}

Compared with the individual reactions to traumatic stressors, the characteristics of organizational traumata carry similar symptomatic components. People who are close to or witnesses of victims of trauma, e.g. in cases of large-scale layoffs, can more easily become secondary victims of trauma. These empathic processes of transmitting trauma within structures of close collaboration have to be differentiated from organizational burnout and from regular stress that occur continuously and at average levels of pressure in today's business world. External and internal factors can contribute to emotional impacts, at times leading to full scale traumatic events; they can lead to emotional exhaustion, depersonalisation, the detachment from clients and co-workers, and also signs of significantly reduced performance (Venugopal 2016).

Organizations can develop systemic traumata that prevent them from functioning properly; in part because its members affected by traumatic events develop defence mechanisms that also display group effects (Kahn 2003). Yet, the clinical indications, from intrusion symptoms, to avoidance and arousal symptoms, up to dissociative tendencies need to prevail also in organizational structures, in order to meet the criteria of acute stress disorder (Kira, Fawzi, and Fawzi 2013).

\section{The Impacts of Traumata Across Organizational Structures}

Huge technological, legal or market specific changes may happen at a rapid pace, requiring fast improvisation, adaptation, fluidity, and utmost flexibility in today's globalized 'competitive, high-velocity environments' (Brown and Eisenhardt 1997, 32). Significant turning points in organizational life-cycles such as large-scale mergers are therefore able to lead to substantial conflicts and subsequently to traumatic episodes. Yet, there are also overwhelmingly huge workloads together with increasing complexities of tasks and jobs, which are among the causes of severe and long lasting traumata. Lacks and shortcomings, uncertainties from unclear responsibilities or insufficiently defined roles also contribute to emotional exhaustion (Daft, Murphy, and Willmott 2014). They may even cause cumulative effects: symptoms such as depersonalisation and detachment from both clients and from positive cooperative behaviour in general; losses of trust and loyalty, eventually transforming an open and empathic corporate culture into a working environment dominated by stress and anxiety (Kahn 2003). Adversity from internal sources 
can originate due to a number of very different reasons, among which there are e.g. mergers, exceedingly fast growth, lack of control mechanisms, inadequate risk management, changes in management followed by abrupt changes in strategies, goal incompatibilities and the like. Negative social support within organizations, due to a lack of interpersonal bonds and relationships can also lead to substantial increases of overall stress factors, similar to job insecurity (Venugopal 2016).

Leadership in times of adversity therefore plays an important role that extends beyond sound managerial competencies and technical controlling of processes and functions. Positive stress interventions can help employees to get back to normal levels of efficiency and performance (Bass and Avolio 1993). However, when putting the focus upon single trauma types in an organizational context, it has to be taken into account that these traumata might not be the only ones, nor the first ones an individual has experienced in his or her lifetime. Bi-dimensional approaches and assessments need to be taken into account in order to cope with potential polyvictimizations (Kira, Fawzi, and Fawzi 2013), i.e. traumata during childhood and systemically induced traumatic stress during a later stage in life or in an organizational context.

In cases of severe adversity and high levels of conflict, the breadth of resources provided by an organization are as important as the speed of delivery of these resources to the employees. Successful organizational trauma support means compassion and comfort delivered by companies to their staff, in order to heal gradually and prevent potential retraumatization (Wilke 2012). The costs of hiring a team of grief counsellors for a certain period of time are generally lower than the negative effects of employees not being supported adequately: lower performance levels, lower standards of customer service, increasing error-proneness and costly error rates, decreasing levels of employee loyalty towards the company, and potential multiplier effects regarding negative communication can generally be associated with higher costs in the long term (Dutton et al. 2002). These developments need to be considered in terms of risk management, since they can have contagious effects on other employees across entire corporate networks. Globalized economic systems and communication structures close to real-time have the potential to accelerate the spillover effects of traumata, so that they can epidemically grow and negatively amplify to full-scale problems in multiple organizational areas (Hatch and Cunliffe 2006; Hormann and Vivian 2005). 


\section{Single Case Study of a Banking Drama}

This paper refers to the author's single case study regarding organizational trauma. It is based upon conducted interviews and the respondents' stories aggregated to narratives, telling a bank's history as seen by its employees. Together with the economic and organizational hard-facts they correspond to the acts of a theatrical drama, in the sense of a banking tragedy in five acts. Times of economic success and continuity were interrupted by unforeseen events, unpredictable traumatic episodes and long periods of severe adversity. A short version of the bank's history serves as introduction to the actual survey results:

The current financial institution had been founded as a small regional bank in Carinthia, back in 1896. For about one century the bank focused primarily on public-sector financing in Carinthia, the southernmost province of Austria. The bank grew slowly but steadily, especially during the post-war decades, after Austria regained full independence as of 1955. The 1992 changes of the bank's top management marks the beginning of rapid expansion to Southeast Europe, thereby relying on the province's guarantees, enabling the bank to have a top rating in the international financial industry. The bank grew from a regional bank to an international finance group, becoming active in Germany, Italy, Bulgaria, Hungary, the Ukraine, Slovenia, Croatia, Serbia, Montenegro and Macedonia, thereby increasing its balance sheet total more than twenty fold.

The first substantial difficulties began to appear in 2006, when Austria's banking supervisory authorities determined that trading losses of more than $€ 300$ million were not visible correctly in the bank's annual reports. New European Union rules that banned government guarantees for banks effectively outlawed the bank's business model. In 2007 one of the large Bavarian based banks purchased the majority, subsequently increasing its share to $67 \%$. The European financial crisis of 2007/2008 started to spread within the banking sector; the financial organization at issue needed substantial amounts of additional capital in order to compensate for the billions of looming bad loans, predominantly accumulated in Southeast Europe.

In 2009, the Austrian authorities formed a special investigation unit, tasked with checking all investments and the entire loan portfolio of the bank in question. In order to avert a major collapse with a potential impact upon the entire Austrian banking sector, the financial institution was nationalized by the Austrian government at 
the end of 2009. According to estimates, the amount of bad loans had exceeded the amount of $€ 10$ billion, several restructuring plans and changes of management followed. In 2014 its banking license was terminated by the Austrian Financial Market Authority (FMA). The bank has since been continued as a partial wind-down unit, i.e. the bank was split into a domestic Austrian unit, sold to an international financial holding company in 2013, a Balkans banking unit, sold to a us-private equity fund and the EBRD during 2014, and a so-called 'bad bank.' It was intended to wind down the entire bad bank with all its portfolios over a period of years; however the winding-down measures have continued to date. The entire amount that the Austrian taxpayer will have to pay is still unknown at this point in time, according to analysts and media reports estimates are in the range of some $€ 10$ to 12 billion, according to official statements the winddown might end around 2020 or later.

\section{Research Design and Methodology}

Qualitative analysis with its foundations in the Constructivist Theory and in Phenomenology has been chosen, in order to be able to focus on the individuals affected by adversity (Eberle 2014). The research design uses the narrative method, focusing on the similarities and differences within thematic segments of the texts, in order to receive a comprehensive representation of the reality of organizational trauma. Qualitative analysis is a method of systematically describing and interpreting the contents of qualitative data (Schreier 2014). It has its foundations in the Constructivist Theory, whose interpretive paradigms have stated that knowledge is not found or discovered per se, but is socially constructed (Schwandt 2003). Individual narratives are constructed as expressions of persons' cognitive and emotional states, thereby including subjective interpretations of events, taking into account aspects of interpersonal, cultural and social relations, in order to generate a social construction of contents (Esin, Fathi, and Squire 2014). Their central paradigms of creating and co-creating knowledge by interacting with others, by participating in their tales, carry the criteria of trustworthiness, credibility and confirmability (Riessman 2008).

Methodically, this approach corresponds with interpretive casestudies, making use of narratives, arguing that cognitive and emotional records gain verbal expression and are being transformed into valid, reliable and confirmable (Denzin and Lincoln 2003; Creswell 2009) statements. Hence, qualitative research 'locates the observer in the world,' trying to 'make sense of, or to interpret, phenomena

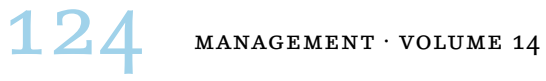


in terms of the meanings people bring to them' (Denzin and Lincoln 2003, 4). Creating meaning, or as narrative psychology phrases it, meaning making concerns both, the respondent and the person doing the research (Josselson and Lieblich 2015). The respective study is embedded in the interpretive theory of the humanities, focusing on the subtle distinctions between the actual spoken words, their context and subtexts, derived from the scientific field of Phenomenology. Subjective impressions and assumptions regarding objects and phenomena in their mode of appearing are being gathered and analysed, presuming that consciousness in a phenomenological sense is always consciousness of something (Creswell 2009; Shinebourne 2011). Lived experience stands for the embeddedness of people, objects and phenomena in a sociocultural, political, economic and historical context, thereby leading the interpretation to both critical and empathic descriptions (Riessman 2008).

\section{Narrative Analysis - Storying Experiences}

Narrative analysis as a method includes various approaches, which enable the researcher to explore how respondents story their experiences (Esin, Fathi, and Squire 2014). By narrating those events retrospectively, the diversities and multifaceted differences and layers of the experiences become visible. The phenomenon of organizational trauma becomes evident, when those aspects are revealed that cause and lead to traumata but also make persons endure, survive and eventually get over traumatic experiences. In order to proceed phenomenologically and stay oriented towards the phenomenon trauma, the researcher needs to identify meaning units within the text (Gill 2014). These meaning units are called narrative segments in the respective study, since they are thematic segments, based upon the experience of events or circumstances that were narrated by the respondents.

The principal method applied follows the studies of Donald E. Polkinghorne (1988; 1997; 2003; 2015), and his guidelines for developing a narrative that enables the researcher to 'synthesize or configure events into an explanation' (Polkinghorne 2003, 16). Narrative as a term refers to both, the respondents' processes of producing an individual story verbally, and to the cognitive scheme of his or her story. The narrative therefore is not just a compilation of happenings. Persons and their perceptions of events have to be interwoven into a whole that unfolds and develops through time (Polkinghorne 1988). In the resp. study, it is the plot that delivers the systemic unity of the narrative. A so-called banking drama in five acts became visible due 
to continuously linking the responses of different personalities to narrative segments, which synthesized and integrated, thereby producing a consistent description.

The collection of data and information was accomplished by oneon-one interviews, therefore all information provided had to be recognized as being filtered through the subjective experience of the respondents, who were not equally articulate and did not necessarily share the same values (Creswell 2009). In order to comply with the demands of sampling strategies in qualitative analysis, the interviewees had to be chosen very carefully. As opposed to quantitative research, where random sampling helps to avoid potential bias-issues of the respondents, the sampling strategy in qualitative research takes the opposite path. It focuses on individuals who are able to provide highly biased information (Rapley 2014). For this reason, it is of utmost importance that the events and their effects - in this case living through adversity and coping with trauma - were being understood by the respondents.

\section{Sampling Strategy and Triangulation}

The resp. study also shows, how the relatively small population of the bank's employees had to be carefully classified and assessed, in order to generate a representative high-quality sample, an 'informationrich case' (Rapley 2014, 56). The sampling decisions were based upon criteria such as the functional and hierarchical roles within the bank, the track record and international banking experience. Interviewees of this study were selected from a group of key employees, i.e. banking experts, over-performers, and/or high potentials with a significant track record of relevant functions and experiences. Each of the interviews lasted some 60 to 90 minutes, conducted according to predefined discussion guidelines, recorded, transcribed, and coded systematically, according to their contents.

The concept and the various processes of triangulation are able to ensure that information is being gathered, compared, and confirmed or disconfirmed; e.g. from different researchers, from different sources, or by means of different methods. This approach leads to a reduction of uncertainties in qualitative research and to an increase of validity of the obtained answers and results. One of these methods that was applied in the resp. study, is 'member checks' (Guba 1981, 83), also dubbed 'circling' (Guba and Lincoln 1991, 257). Both of these descriptive terms indicate that the collected information from a respondent is being circulated among some or all of the other interviewees. It is being checked among the members of the

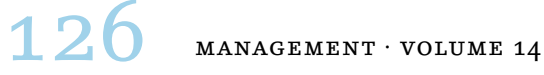


group of respondents, in order to be confirmed, critically questioned or even disconfirmed.

When replies were taken back to the other respondents, the main purpose was to check them regarding plausibility, applicability, and consistency but also regarding the initial interpretations and conclusions (Krefting 1991). As opposed to multiple-case studies or crosscase analysis, the resp. single-case study focuses on a single realworld case. In order to ensure internal and external validity, multiple sources of evidence were included in the process of data collection (Yin 2018). The rationale behind using multiple sources of evidence is the strategic goal of reliable and valid methods, which 'essentially provide multiple measures of the same phenomenon' (Yin $2018,128)$, in order to render the narrative as accurately as possible. The triangulation of both data and theories enables single-case studies to strengthen the validity and reliability of the survey. By following these principles, the strengths of a single-case method are able to explain temporal sequences and causal relations in the complex processes of organizational trauma.

\section{Narrative Analysis: Coping With Trauma}

When the bank's problems started to become visible during the mid2000 years, they were initially ignored and attributed to the spheres of rumours and bad media coverage. The long path from self-motivation to fears, frustrations, internal and external stressors, altogether resulting in trauma, was just about to begin. Denial was one of the first and most frequent reactions among employees. During the years after the nationalization of the institution and the beginning of massive restructuring the intensities of denial started to vary. Later, the forms of denial and also the denial of responsibility started to shift, depending on the position and location of the employees. After more and more people started to gradually accept that the organization was in the most serious of troubles, denial could not be kept up any longer. Employees were struggling with numerous of the shattering facts, entering into processes of having to accept a new reality. Most of the respondents designated the term chaotic to the period between 2011 and 2016, whereby the emotions gradually shifted from irritation, disappointment and insecurity to chaos and panic, followed by a loss of perspective and eventually resignation.

\section{Deteriorating Work Atmosphere}

An increase of erratic internal and external waves of pressure followed. Splitting and winding down an entire organization within 
a tight legal, economic and political framework of local and governmental authorities was perceived as extreme external pressure. Huge workloads under these circumstances - a looming atmosphere of general suspicion - pushed many of the remaining employees to their resilience borders. The internal pressure and stress was predominantly perceived as a function of external pressure and had many shapes and facets. Loss of mutual trust and the implementation of processes, in which employees were given a 6 to 12 or even 18 months notification in advance as to when their appointments would end, slashed their motivation. Putting employees on a longterm dismissal list, but at the same time implicitly expecting that all work would get done flawlessly, led to a substantial increase of internal tensions and pressure.

Running down the staff numbers in a drastic manner led to fierce competition, aggressiveness, frustration, and anger. Feelings of fear, of being left alone, as well as a general lack of trust became stronger. However, after the fifth rotation of management, of strategies, and priorities, many employees burned out, gave up, and detached themselves emotionally from both people and structures. Furthermore, the stressors were such that the number of sick leaves rose drastically; the reasons behind these developments were multifarious: physical, psychosomatic, emotional and mental exhaustion, a complete lack of trust and positive feedback, internal and external pressure, aggression and fear, just to name a few. The physical and psychological results of such traumatic overexertion led to depression, lethargy, burnout phenomena, emotional and social detachment, finally resulting in minor and major health problems. Among the symptoms reported by the interviewees were severe sleeping disorders, circulation problems, dangerous rises in blood sugar, putting on weight, concentration problems, mild but also severe forms of depression, as well as an increase in relationship and partnership issues. Only a very small number of employees was able to stay physically and mentally unharmed and intact.

\section{Variants of Coping with Trauma}

With a few exceptions, the remaining employees and their management were psychologically on their own. Those staff members who were able to rely on a strong background of supportive families and friends were generally better off; but many people within the bank's international network of organizations worked as expatriates, i.e. family and friends were often not available, at least not physically. Coping with organizational trauma for these people meant that

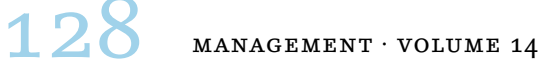


they had to 'process everything inside and alone, which was painful, stressful and lonely' (' $R$ ' for replies given by individual respondents of the respective study).

Without professional support, most people tried to invent and establish their own 'survival strategies' (R), in order not to be hit by the ongoing organizational trauma. Some of the respondents developed insight into the traumatic events and episodes only after they had left the bank, 'while you are inside [a period of traumatizing events], you do not see and understand what is going on with you. You think that you know, but that is an illusion' (R). Some of the 'survival strategies' were mechanistic, some were cognitive and yet others were emotional approaches. Others shifted their focus of work on short-term goals, and yet others stopped socializing with former colleagues, 'in order to protect my energy' (R).

When the organizational systems were collapsing, one of the respondents observed coping strategies of colleagues. They consisted of efforts to become 'over-positive, over-productive, or overmotivated' (R), in order to counterbalance and compensate for the actual loss of perspective and positive feedback by investing even more self-energy into the given situation. Yet, another form of coping with the ongoing traumatic events was to detach oneself from the workplace and to 'fade out everything' (R). However, this behaviour of total detachment frequently led to a situation, in which the respective persons became mentally 'unable to terminate the contract' $(\mathrm{R})$, and were partly relieved, when the bank eventually took the decision of terminating their employments.

Among the coping strategies of employees, who had at least some professional or scientific information regarding organizational trauma, burnout, resilience, conflict resolution and the like, were different perceptions and approaches. Due to their academic background or in-service training during their professional careers, they perceived that the vast majority of employees 'simply did not know what to do' $(\mathrm{R})$, when the organizational systems crumbled. With the exception of those pre-trained and pre-informed employees, 'people were unaware of most of these things and functioned in an auto-pilot way' (R), according to one of the respondents, a senior HR-professional.

As a consequence of this, one of the suggested paths in order to cope with or at least mitigate the worst impacts of trauma on an organizational level, was to inform and train the remaining staff in the fields of self-awareness, self-compassion, mindfulness, and resilience. 'You cannot support someone "from an empty cup"' (R), was one of the metaphors used to describe that a stable and resilient self. 
Together with the basics of psychological skills, a framework of emotional intelligence and empathy, it is a foundation for interpersonal help within collapsing organizations.

Another aspect that put additional pressure onto coping strategies was the massive media coverage across time. The importance of good and stable social contacts was therefore emphasized by most of the respondents. Those who didn't have a strong social support from their socioenvironment were generally perceived as having bigger problems in establishing coping strategies and detaching themselves from organizational trauma as it evolved. Those who turned to external support, did that mostly after their employments and due to the fact that their posttraumatic symptoms didn't subside. 'After one year of pills and self-fight' (R), one respondent confessed, 'I found it hard to accept that I needed external support' (R).

\section{Reflecting the Periods of Adversity}

When reflecting upon their experiences the respondents of the resp. study gave several pieces of advice. One part addressed the staff, the other one the leadership of organizations. Having lived through organizational trauma the respondents recommended employees to 'try to revert to internal or external support as soon as possible' (R), because long-lasting developments such as the one they had gone through drained 'energy and health' out of everyone involved in an extreme manner. Employees should 'not pretend to be able to constantly perform at or beyond their maximum energy level' (R); they should at all times be aware of their individual capacity limits, and they should start to look for another job before their physical and mental energy reserves become depleted. The importance of social contacts was emphasized by almost all of the interviewees as being essential in order to literally ride out the heavy storms of organizational trauma. What some of the respondents added, was that every employee should try to keep his or her life aside from the respective company, besides her or his job, 'being a member of the system, but not a part' (R). Watching one's limits, listening to one's feelings, not letting the system control oneself, and believing in oneself were general statements that do not go without certain vagueness; however, these recommendations were formulated straight from a position of unmediated traumatic experience.

Similar to this, some of the respondents claimed, that their 'subjective risk-awareness and the ability to prioritise' (R) had improved significantly, and that they had transformed their bitter experiences into a deeper and more profound insight into human nature. Fur-

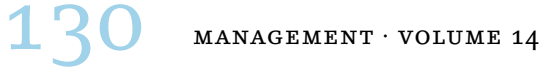


thermore, various social skills were mentioned, such as 'connecting to people,' as well as an enhanced capacity of handling one's private and professional life, thereby balancing out the different demands and challenges. Having fought through adversity had also improved the self-awareness, self-respect, and self-confidence of some of the respondents to at least the pretrauma-levels.

\section{Discussion and Conclusion}

All of the research participants of the resp. study initially displayed high levels of motivation and preparedness to invest plenty of energy and significant personal dedication to the demanding tasks they were confronted with. Most of them had good managerial and social skills, they were extraverted personalities pursuing their individual career paths. It was only with time that these interviewees - without exception key employees of the bank - found out that they had underestimated the forces and pressures of organizational change that transformed into a long-term nightmare of adversity, resulting in traumatizing events that affected almost all of them. Trauma theory categorizes such sequences of adversity as impersonal traumatic events, since they are happening to the victim almost always without direct and causal involvements of persons. These aspects of anonymity frequently aggravate and complicate the processes of understanding and of rationalizing.

Despite the fact that the so-called pretrauma reality schemes were fully intact at the beginning, the capability of managing emotional distress started to fade and intense, across time even overwhelming feelings of fear, anger, unreality, shame, and guilt prevailed. Trauma theory shows that confrontations with sudden traumatizing events and the threat of additional adversity in the future keep increasing the state of anxiety (LaBar 2016); they are physically and mentally exhausting, in parts due to the huge cognitive dissonance between the actual state of traumatization and the desired state of positive pretrauma expectations. The long term gap between highly incompatible cognitions lead to chronic and hidden sicknesses to reappear, also increased sleeplessness and feelings of depression, emotional exhaustion and depersonalisation.

Getting negative national and international media coverage in addition to the above-mentioned reality, worsened the situation beyond bearable levels. The experience of daily micro traumata and having to remain reachable at virtually all times, drained enormous amounts of energy from each and every employee, also from the highly self-motivated ones. 
The switch from denial to chaos and resignation, from self-motivation to emotional emptiness and depression cannot be managed en passant. Serious issues that affect the entire staff of an organization need leadership action, such as deciding to take on professional help. The argument of insufficient financial resources to hire external coaches and psychological help is common but not valid. The fact that emotional stability leads to higher performance, less errors, less sick-leaves, i.e. higher overall productivity, justifies such investments. If an organization's management leaves its employees on their own, the stressors may lead to physical, psychosomatic, or mental exhaustion, thereby putting massive pressure on productivity.

External experts teaching mental and physical techniques in the fields of resilience as well as the deregulation of emotions and impulses are able to help with situations of chaos, fear, insecurity, passiveness, internal and external pressure. They can also offer valuable support in situations where the majority of the staff has underestimated the complexity, the pressure and scale of economic transformation processes, their potential adversities and negative consequences with regards to mental, physical, and motivational exhaustion. Times of adversity and organizational trauma often go hand in hand with unprecedented changes of management (Kelloway et al. 2005). This makes it even more important to include external psychological support into all of the transformational or change-related strategic planning. In cases of friendly or hostile takeovers, in cases of dynamic changes and huge reorganizations, planning and providing of sufficient resources seems mandatory.

In view of the results of the resp. study, it seems unnecessary that employees have to cope with organizational trauma all by themselves, their partners, friends, and colleagues at work. They are technically trained to fulfil business related tasks; as individuals they are more or less socially skilled, but they are not properly trained to mentally or emotionally endure or solve lengthy situations of collapsing organizations. Such skills have to be brought into organizations, in order to also educate leaders and managers as role models for all other employees, regarding resilience, mindfulness and other psychological basic skills (Powley 2012; James and Wooten 2012). These external supports should not stop during the immediate aftermath of trauma but be extended to help with all of the potential posttraumatic symptoms, from restlessness to worry, intrusive thoughts, continuously reflecting the past and the like. The improvement of business practices by supporting coping techniques means that compa-

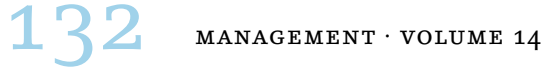


nies become aware and also prepared - organizationally and emotionally - to cope with traumata; a step which is in line with the approaches of modern risk management and strategic planning.

\section{References}

American Psychiatric Association. 1980. Diagnostic and Statistical Manual of Mental Disorders. 3th ed. Washington, Dc: American Psychiatric Association.

- 2013. Diagnostic and Statistical Manual of Mental Disorders. $5^{\text {th }}$ ed. Washington, Dc: American Psychiatric Association.

Bass, B. M., and B. J. Avolio. 1993. 'Transformational Leadership and Organizational Culture.' Public Administration Quarterly 17 (1): 11221.

Bhamra, R., S. Dani, and K. Burnard. 2011. 'Resilience: The Concept, a Literature Review and Future Directions.' International Journal of Production Research 49 (18): 5375-93.

Bonanno, G. A. 2004. 'Loss, Trauma, and Human Resilience.' American Psychologist 59 (1): 20-8.

Bonanno, G. A., and A. D. Mancini. 2012. 'Beyond Resilience and PTSD: Mapping the Heterogeneity of Responses to Potential Trauma.' Psychological Trauma: Theory, Research, Practice, and Policy 4 (1): 7483.

Bonanno, G. A., A. Papa, and K. O'Neill. 2002. 'Loss and Human Resilience.' Applied and Preventive Psychology 10:193-206.

Bonanno, G. A., S. A. Romero, and S. I. Klein. 2015. 'The Temporal Elements of Psychological Resilience: An Integrative Framework for the Study of Individuals, Families, and Communities.' Psychological Inquiry 26 (2): 139-69.

Bridges, W. 1995. JobShift: How to Prosper in a Workplace Without Jobs. Reading, mA: Perseus Books.

Brown, S. L., and K. M. Eisenhardt. 1997. 'The Art of Continuous Change: Linking Complexity Theory and Time-paced Evolution in Relentlessly Shifting Organizations.' Administrative Science Quarterly 42 (1): 1-34.

Caza, B. B., and L. P. Milton. 2012. 'Resilience at Work. Building Capability in the Face of Adversity.' In The Oxford Handbook of Positive Organizational Scholarship, edited by K. S. Cameron, and G. M. Spreitzer, 895-908. New York, NY: Oxford University Press.

Creswell, J. W. 2009. Research Design: Qualitative, Quantitative, and Mixed Methods Approaches. Thousand Oaks, cA: Sage.

Daft, R. L., J. Murphy, and H. Willmott. 2014. Organization Theory and Design: An International Perspective. Andover: Cengage.

Denzin, N. K., and Y. S. Lincoln, eds. 2003. The Landscape of Qualitative Research: Theories and Issues. Thousand Oaks, cA: Sage.

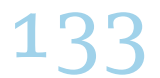


Dutton, J. E., P. J. Frost, M. C. Worline, J. M. Lilius, and J. M. Kanov. 2002. 'Leading in Times of Trauma.' Harvard Business Review 80 (1): 5461.

Eberle, T. S. 2014. 'Phenomenology as a Research Method.' In The Sage Handbook of Qualitative Data Analysis, edited by U. Flick, 184-202. London: Sage.

Esin, C., M. Fathi, and C. Squire. 2014. 'Narrative Analysis: The Constructionist Approach.' In The Sage Handbook of Qualitative Data Analysis, edited by U. Flick, 203-16. London: Sage.

Everly, G. S. 1995. 'An Integrative Two-Factor Model of Post-Traumatic Stress.' In Psychotraumatology: Key Papers and Core Concepts in Post-Traumatic Stress, edited by G. S. Everly, and J. M. Lating, 2748. New York, NY: Plenum Press.

Ford, J. D., D. J. Grasso, J. D. Elhai, and C. A. Courtois. 2009. Posttraumatic Stress Disorder: Scientific and Professional Dimensions. Burlington: Elsevier.

Gill, M. J. 2014. 'The Possibilities of Phenomenology for Organizational Research.' Organizational Research Methods 17 (2): 118-37.

Guba, E. G. 1981. 'Criteria for Assessing the Trustworthiness of Naturalistic Inquiries.' Educational Communication and Technology 29 (2): 75-91.

Guba, E. G., and Y. S. Lincoln. 1991. Effective Evaluation: Improving the Usefulness of Evaluation Results Through Responsive and Naturalistic Approaches. San Francisco: Jossey-Bass.

Hatch, M. J., and A. L. Cunliffe. 2006. Organization Theory: Modern, Symbolic, and Postmodern Perspectives. New York: Oxford University Press.

Hormann, S., and P. Vivian. 2005. 'Toward an Understanding of Traumatized Organizations and How to Intervene in Them.' Traumatology 11 (3): 159-69.

James, E. H., and L. P. Wooten. 2012. 'Orientations of Positive Leadership in Times of Crisis.' In The Oxford Handbook of Positive Organizational Scholarship, edited by K. S. Cameron, and G. M. Spreitzer, 882-94. New York, NY: Oxford University Press.

Josselson, R., and A. Lieblich. 2015. 'Narrative Research and Humanism.' In The Handbook of Humanistic Psychology: Theory, Research, and Practice, edited by K. J. Schneider, J. F. Pierson, and J. F. Bugental, 321-34. Thousand Oaks, cA: Sage.

Kahn, W. A. 2003. 'The Revelation of Organizational Trauma.' The Journal of Applied Behavioral Science 39 (4): 364-80.

Kelloway, E. K., N. Sivanathan, L. Francis, and J. Barling. 2005. 'Poor Leadership.' In Handbook of Work Stress, edited by J. Barling, E. K. Kelloway, and M. R. Frone, 89-112. Thousand Oaks: Sage Publications.

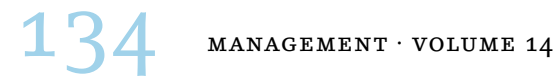


Kira, I. A., M. H. Fawzi, and M. M. Fawzi. 2013. 'The Dynamics of Cumulative Trauma and Trauma Types in Adults Patients With Psychiatric Disorders: Two Cross-Cultural Studies.' Traumatology 19 (3): 179-95.

Kleber, R. J. and P. G. van der Velden. 2009. 'Acute Stress at Work.' In International Handbook of Work and Health Psychology, edited by C. L. Cooper, J. C. Quick, and M. J. Schabracq, 268-91. Chichester: Wiley.

Kolk, B. A., van der. 2007. 'The Body Keeps the Score: Approaches to the Psychobiology of Posttraumatic Stress Disorder.' In Traumatic Stress: The Effects of Overwhelming Experience on Mind, Body, and Society, edited by B. A. van der Kolk, A. C. McFarlane, and L. Weisaeth, 214-41. New York: Guilford.

Krefting, L. 1991. 'Rigor in Qualitative Research: The Assessment of Trustworthiness.' The American Journal of Occupational Therapy 45 (3): 214-22.

LaBar, K. S. 2016. 'Fear and Anxiety.' In Handbook of Emotions, edited by L. Feldman Barrett, M. Lewis, and J. M. Haviland-Jones, 751-73. New York: Guilford.

McFarlane, A. C. and G. de Girolamo. 2007. 'The Nature of Traumatic Stressors and the Epidemiology of Posttraumatic Reactions.' In Traumatic Stress: The Effects of Overwhelming Experience on Mind, Body, and Society, edited by B. A. van der Kolk, A. C. McFarlane, and L. Wei-aeth, 129-154. New York: Guilford.

Mintzberg, H. 1983. Structure in Fives: Designing Effective Organizations. Englewood Cliffs, NJ: Prentice-Hall.

Parad, H. J., and G. Caplan. 1960. 'A Framework for Studying Families in Crisis.' Social Work 5 (3): 3-15.

Polkinghorne, D. E. 1988. Narrative Knowing and the Human Sciences. Albany, NY: State University of New York Press.

- 1997. 'Reporting Qualitative Research as Practice.' In Representation and the Text: Re-Framing the Narrative Voice, edited by W. G. Tierney and Y. S. Lincoln, 3-22. Albany, NY: State University of New York Press.

- 2003. 'Narrative Configuration in Qualitative Analysis.' In Life History and Narrative, edited by J. A. Hatch and R. Wisniewski, 523. London: Falmer.

- 2015. 'Possibilities for Action: Narrative Understanding.' Narrative Works: Issues, Investigations, and Interventions 5 (1): 153-73.

Post, R. M. 1992. 'Transduction of Psychosocial Stress Into the Neurobiology of Recurrent Affective Disorder.' The American Journal of Psychiatry 149 (8): 999-1010.

Powley, E. H. 2012. 'The Process and Mechanisms of Organizational Healing.' The Journal of Applied Behavioral Science 49 (1): 42-68.

Rapley, T. 2014. 'Sampling Strategies in Qualitative Research.' In The Sage Handbook of Qualitative Data Analysis, edited by U. Flick, 4963. London: Sage. 
Reason, J. 2016. Managing the Risks of Organizational Accidents. Abingdon: Taylor and Francis.

Riessman, C. K. 2008. Narrative Methods for the Human Sciences. Thousand Oaks, cA: Sage Publications.

Ringel, S. and J. R. Brandell, eds. 2012. Trauma: Contemporary Directions in Theory, Practice, and Research. Thousand Oaks, cA: Sage.

Schein, E. H. 2010. Organizational Culture and Leadership. San Francisco: Jossey-Bass.

Schreier, M. 2014. 'Qualitative Content Analysis.' In The Sage Handbook of Qualitative Data Analysis, edited by U. Flick, 170-83. London: Sage.

Schwandt, T. A. 2003. 'Three Epistemological Stances for Qualitative Inquiry: Interpretivism, Hermeneutics, and Social Constructionism.' In The Landscape of Qualitative Research: Theories and Issues, edited by N. K. Denzin and Y. S. Lincoln, 292-331. Thousand Oaks, cA: Sage.

Shinebourne, P. 2011. 'Interpretative Phenomenological Analysis.' In Qualitative Research Methods in Psychology: Combining Core Approaches, edited by N. Frost, 44-65. Maidenhead: McGraw-Hill Education.

Sutcliffe, K. M., and M. K. Christianson. 2012. 'Managing the Unexpected.' In The Oxford Handbook of Positive Organizational Scholarship, edited by K. S. Cameron, and G. M. Spreitzer, 843-54. New York, Ny: Oxford University Press.

Venugopal, V. 2016. 'Understanding Organizational Trauma: A Background Review of Types and Causes.' Journal of Business and Management 18 (10): 65-9.

Vogus, T. J., N. B. Rothman, K. M. Sutcliffe, and K. E. Weick. 2014. 'The Affective Foundations of High-Reliability Organizing.' Journal of Organizational Behavior 35 (4): 592-6.

Wilke, G. 2012. 'Leaders and Groups in Traumatized and Traumatizing Organizations: A Matter of Everyday Survival.' In Trauma and Organizations, edited by E. Hopper, 195-214. London: Karnac Books.

Wilson, J. P. 1995. 'The Historical Evolution of PтSD Diagnostic Criteria.' In Psychotraumatology: Key Papers and Core Concepts in PostTraumatic Stress, edited by G. S. Everly, and J. M. Lating, 9-26. New York, NY: Plenum Press.

Yin, R. K. 2018. Case Study Research and Applications: Design and Methods. Thousand Oaks: Sage.

This paper is published under the terms of the Attribution-

NonCommercial-NoDerivatives 4.0 International (CC BY-NC-ND 4.0)

License (http://creativecommons.org/licenses/by-nc-nd/4.o/). 